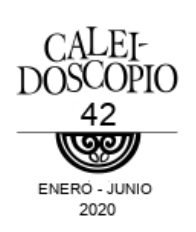

\title{
Presentación del dossier sobre Artes Visuales
}

Presentation of the dossier on Visual Arts

JUAN MANUEL VIZCAÍNO MARTÍNEZ

Coordinador editorial del dossier

\section{ALGUIEN TIENE QUE CONTAR NUESTRAS HISTORIAS}

Este dossier de la revista Caleidoscopio es resultado de un conjunto de alianzas y sinergias interuniversitarias, resultado de un discreto, pero oficioso viaje desde el Centro de Ciencias Sociales y Humanidades de la Benemérita Universidad Autónoma de Aguascalientes, hasta la Licenciatura en Artes Visuales, de la Universidad de las Artes en el Instituto Cultural de Aguascalientes. Este viaje académico interinstitucional es síntoma de una apertura de fronteras a través de la que migra un conjunto de fuerzas vivas que atraviesan las distancias institucionales con sus textos, con sus historias.

Como programa académico, la Licenciatura en Artes Visuales nace en el 2002 en el Centro de Artes y Oficios, para migrar en agosto del 2003 a un complejo industrial abandonado por Pemex a finales del siglo XX, lo que, por reducción simbólica, implica una migración de modelo artístico, desde las artes avecindadas con la práctica de los oficios tradicionales, a las artes inscritas en un complejo 
postindustrial abandonado que, como práctica de paracaidismo, se hace un lugar en alguna esquina de la cultura.

Fue hasta el 2008 que se funda la Universidad de las Artes con la intención de congregar un conjunto de programas académicos de educación superior y técnico superior en un mismo territorio, ubicado ahora en los antiguos talleres del ferrocarril, como resultado de un esfuerzo estatal por recuperar las instalaciones abandonadas por la privatización de Ferrocarriles de México, y en pos de recuperar entonces una tradición perdida (vendida) por efecto de las políticas neoliberales, a través de la toma de territorio del campo profesional de las artes.

En este caso, tanto en la migración al complejo de Pemex como en la migración al complejo ferrocarrilero, nos es posible observar que las artes y su profesionalización son parte de la campaña estatal de la modernidad hidrocálida contemporánea por recuperar los vestigios de una tradición perdida en una carrera de progreso aparente, atravesando y habitando en los vacíos, en los huecos y aperturas derivadas de la industrialización y la privatización por operación de las modernidades.

Ahora entonces, existe un correlato menos visible en esta trayectoria, el relato de quienes hemos vivido este viaje y que, por la existencia de ciertas condiciones personales, familiares y sociales, hemos encontrado un territorio en estos programas académicos para hacer cultura, para establecer y habitar nuestra casa de estudios, nuestra alma mater, la Universidad de las Artes; nosotros quienes, como las instituciones, hemos experimentado las consecuencias del abandono de las tradiciones y la privatización de las culturas, para recuperarnos y reconstruirnos en las prácticas artísticas contemporáneas, como 
un asidero vivencial del pensamiento nómada que encarnamos y nos congrega como comunidad universitaria.

Es ahora, con motivo de la presentación de este dossier del Número 42 de la revista Caleidoscopio de la Universidad Autónoma de Aguascalientes, que se coordinó en la LAV, que nos encontramos en condiciones de ofrecer un registro transversal en las plataformas editoriales universitarias, registro de la vida académica de nuestro Programa, una oportunidad de contar nuestras historias en las presentes condiciones socioculturales, a manera de un ejercicio colaborativo y comunitario que nos permita evaluar, valorar y determinar nuestra agenda académica, sus potencias y posibilidades como parcela de la vida universitaria, artística y cultural.

En lo subsecuente, les invitamos a visitar los textos aquí publicados como parte de este viaje de profesionalización y academización de las artes y las culturas en la Universidad de las Artes, no sin antes agradecer por nuestra parte a cada una de las autoras y autores de los textos, así como al equipo editorial de la revista, quien abrió brecha para hacer este itinerario posible.

CÓMO CITAR ESTE ARTÍCULO

Vizcaíno Martínez, J. M. (2020). Presentación del dossier sobre artes visuales. Caleidoscopio - Revista Semestral de Ciencias Sociales y Humanidades, 23(42), 9-11. doi:10.33064/42crscsh2178 